\title{
Methods for Obtaining Silver Nanoparticles - a Review
}

\author{
M.E. Ing. Risham Singh Ghalot \\ Engineering Faculty \\ Rezekne Academy of Technology \\ Rezekne, Latvia \\ singhrisham93@gmail.com
}

\author{
Dr. Sc. Ing. Lyubomir Lazov, Prof. \\ Engineering Faculty \\ Rezekne Academy of Technology \\ Rezekne, Latvia \\ Lyubomir.Lazov@rta.lv
}

\begin{abstract}
Silver has been part of active medical use for treatment and disinfection from ages, even in the present times. Particularly relevant today is the question of the effect of silver nanoparticles on bacteria and viruses, including against COVID-19. The study reviews distinct methods for producing silver nanoparticles. The comparison and preferences of different methods based on their classification and features are reviewed. The main goal of this study is to reveal the top-notch method and their benefits and prospects of the possibilities of the method - laser ablation, as a costeffective and environment friendly technology for generating silver nanoparticles in an aqueous environment. The method of Pulsed Laser Ablation in Liquid for obtaining nanoparticles is explained in detail. The paper is divided into several main parts, starting with a briefing on silver and its nanoparticles and is followed by various methods for their production.
\end{abstract}

Keywords - Silver Nanoparticles, Laser Ablation, Material Processing, Nanoparticles, Pulsed Laser Ablation in Liquid.

\section{SILVER NANOPARTICLES}

Silver (Ag) is the remarkably vital antimicrobial agent usable before the introduction of antibiotics. [1] Silver Nanoparticles (Ag NPs) are nanoparticles (NPs) of Ag produced via nanotechnology of size varying between $1-$ $100 \mathrm{~nm}$ in any dimension. [2] Ag NPs have been the research theme from the past several decades because of size, shape, antimicrobial effects, chemical stability, catalytic activity high conductivity, and other extraordinary characteristics. Several techniques for obtaining Ag NPs have been priorly researched such as laser ablation, gamma irradiation, electron irradiation, chemical reduction, photochemical methods, microwave processing, and synthetic biological methods. [3]
Nanotechnology is an essential field of present-day research dealing in design, synthesis, and administrating particle structures ranging, approximately, 1-100 nm. NPs have several applications in fields of medication, cosmetics, Eatables, substantial well-being, optics, biomedical sciences, chemical \& space industries, electronics and many more. Synthesised Ag NPs are used for various pharmaceutical applications. Few are mentioned below: [3] [4]

- The remedy of ulcerative colitis \& acne

- Remedy of dermatitis

- Inhibition of HIV-1 replication

- Molecular imaging of cancer cells

- Disclosure of viral structures (SERS \& Ag nanorods)

- Antimicrobial effects against infectious organisms

- Varnishing of surgical mesh for pelvic reconstruction

- Varnishing of breathing mask patent (used in COVID19 pandemic) 


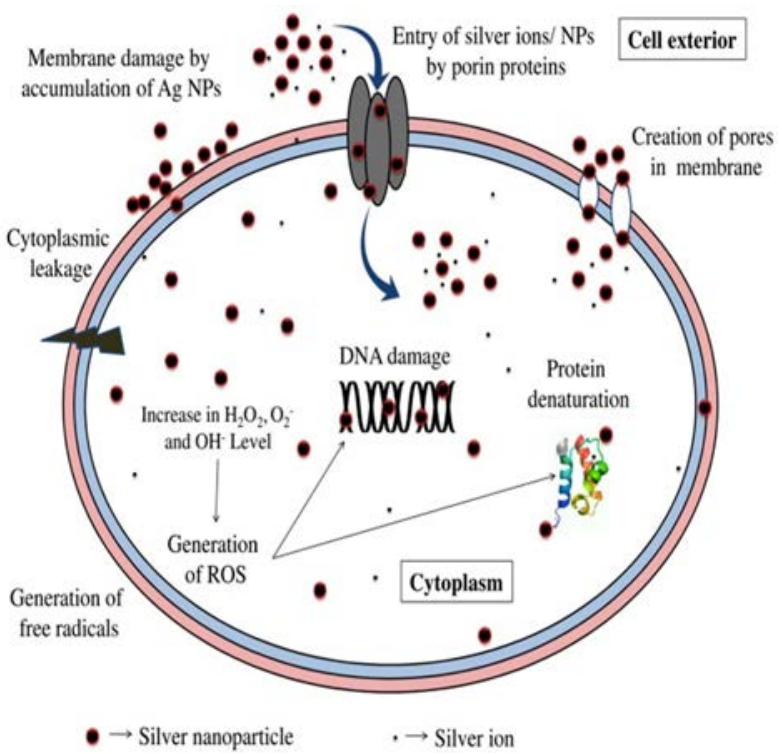

Figure 1: Bio-mechanism of antibacterial action of silver nanoparticles and silver ions [5]

Depending on reducing sources and mechanism, there are three prime methods to formulate Ag NPs. Physical processes usually operate with laser impulse energy to reduce Ag from volume to atoms and ions. Whereas, chemical and biological methods utilise reducing synthetic and organic agents, respectively, to reduce Ag ions from their harbinger into metallic Ag atoms. [6]

\section{FACTS ABOUT SILVER AND AG NPS}

Over the centuries, because of alteration in nomenclature, the complexity has remained among scientists, that the use of Ag, commercially, is accessible for over 100 years and are used as wound remedy, conductive/antistatic composites, catalysts, as a biocide, and many more is undeniable. The use of nanoscale Ag has a protracted, distinct, and complexed past, that is why recently, an exceptional study of AgNPs nomenclature has been conducted approximately over the past 120 years, which did not use "nano" classification. [7]

\section{A. FACTS [7] [1]}

- In 702-705, Gabor listed the demand for silver nitrate being used as a medical agent, for the first time.

- In 980 A.D. the Persian physicist-Avicenna registered silver filings as a blood purifier, which countered the heart palpitations and offensive breath.

- In 1520, Paracelsus introduced a treatment, which is in use until present, used silver internally and applied silver nitrate as a caustic for the treatment of wounds.

- In 1614, Angelo Sala gave silver nitrate internally as a counterirritant, as a purgative, and for the treatment of brain infections.
- In 1889, M. C. Lea reported the fusion of a citratestabilized silver colloid and the obtained size for the particles was between 7 - $9 \mathrm{~nm}$.

- At present, every year, an estimate of about 320 tons of nano-silver is manufactured and used universally.

\section{METHODS FOR PROCESSING AG NPS}

The synthesis of Ag NPs has been examined extensively and, over the years, several procedures have been offered for the processing. [8] Under two important techniques, NP Production is classified (figure 2):

- Top-down Approach: - In this, an external force applies to a solid bulk that guides it to breaking it into nanostructures.

- Bottom-up Approach: - It begins at the atomic scale $\&$ produces the NPs, till the required size $\&$ shape is obtained. [9]

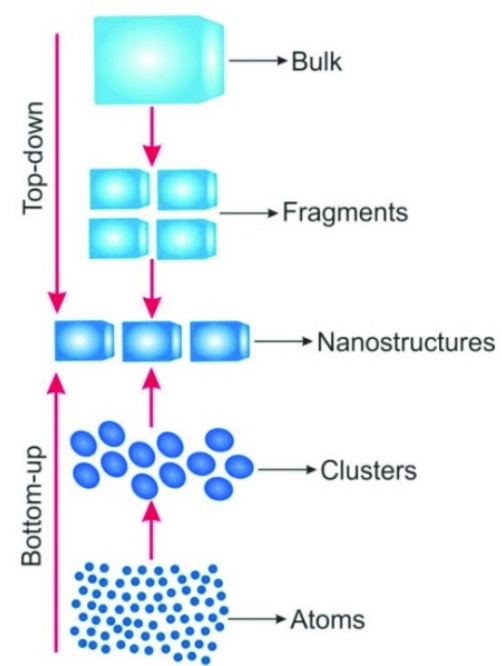

Figure 2: Schematic representation of 'top-down' and 'bottom-up' approaches for the synthesis of nanoscale materials. [10]

Different methods to synthesise Ag NPs; such are Physical, Chemical, and Biological Methods are explained below:

\section{A. PHYSICAL METHODS}

Having non-synthetic liquids in the groomed thin films and the NPs distribution having consistency are some of the advantages of physically synthesised NPs as compared to that of chemical methods. [3] These can be categorised into different types of processes such as [8]

- Arc Discharge - The original element is vaporized via an arc discharge between electrodes pursued by condensation, nucleation, and production of NPs. [11]

- High-Pressure Magneton Sputtering - It is a bottomup mechanism \& dwells in condensation of a supersaturated vapour in a flow of cold inert gas and this vapour atmosphere is procured by various methods as 
thermal evaporation, laser ablation, magnetron plasma sputtering, etc. [12]

- Laser Ablation - The process separated the layers from solid bulk materials by utilising a laser beam for utmost accuracy. The laser beam irradiates the top layer, concluding that it has been disclosed to laser beam radioactivity. [13]

\section{B. CHEMICAL METHODS}

The synthetic procedure became famous via several works by John Turkevich in the 1950s, a professor of chemistry in Princeton and a pioneer in the field of catalysis. The synthetic reduction by organic and inorganic reducing agents is the most appropriate and suggested method for generating the Ag NPs. Various reducing agents such as sodium citrate, ascorbate, elemental hydrogen, polyol process, are commonly used for silver ions $\left(\mathrm{Ag}^{+}\right)$ reduction in all kind of solutions, whether it is liquid or non-liquid. These agents dwindle $\mathrm{Ag}^{+}$and manage the formation of silver $\left(\mathrm{Ag}^{0}\right)$. [14] Protective agents are a priority to be used to stabilise the breaking-up NPs during metal NPs preparation and secure them from being consumed or bind onto NPs surfaces, escaping their aggregation. [15] The presence of surface-active agents like acids, amines or alcohol, comprising functionalities for cooperation with particle skin can stabilise the growth of particle, and conserve particles from sedimentation, accumulation, or losing surface properties. [3] The chemical methods can be differentiated into various types also: [16] [8]

- Photochemical - It involves Ultraviolet irradiation of the solid forerunner solution in an electroncontributing reagent. With this method, NPs are produced under solid-state status \& at low temperatures. [17]

- Microemulsion - It is thermodynamically balanced colloidal diffusion of water in oil or vice-versa, balanced by a surfactant. Ultralow interfacial tension, large interfacial area, and being thermodynamically stable and monodispersed NPs, are the advantages of this method. [18]

- Hydrothermal - It is a solution reaction-based approach and can produce NPs in a room- to a very high- temperature. [19]

- Chemical Reduction - A prevailing synthesis method of Ag NPs, by organic \& inorganic reducing agents such as sodium citrate, ascorbate, sodium borohydride $\left(\mathrm{NaBH}_{4}\right)$, elemental hydrogen, $\mathrm{N}$ dimethylformamide (DMF), \& poly (ethylene glycol)-block copolymers are used for $\mathrm{Ag}^{+}$ions reduction. [3]

- Electrochemical Mechanism - A traditional method, utilizing a two-electrode system for the electrochemical synthesis. It has advantages over other bottom-up approaches (purity of NPs). [20]

\section{BIOLOGICAL METHODS}

The concept of Green synthesis comprises polysaccharides, organic and irradiation mechanisms, which have preferences over traditional methods requiring synthetic agents associated with substantial harms. [21] It has been gaining interest because this process uses organic agents such as bacteria, fungi, yeast, and plant, making it a simple, cost-effective, and eco-friendly mechanism. It has a regular chemical reduction, with the reducing agent as natural agents. [8] Ag NPs can be natural synthesised (a.k.a. green synthesis) with the help of:

- Bacteria - It has great abilities to diminish heavy metal ions \& is the most prescribed for manufacturing NP. E.g.: Pseudomonas stutzeri and Pseudomonas aeruginosa. [22]

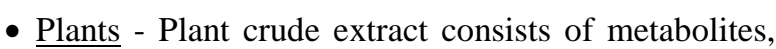
which are highly important for the reduction of ionic into bulk metallic NPs production. E.g.: Acalypha indica, Alternanthera sessilis. [23]

- Fungi - These are interesting reducing agents for the biosynthesis of Ag NPs as they offer high tolerance to metals and are handled easily. The extraction of extracellular proteins from fungi contributes to the stability of the NPs. E.g.: Fusarium oxysporum. [24]

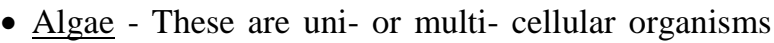
residing in the distinct surrounding. Synthesis at low temperature with higher energy efficiency, less toxicity, \& the risk to the environment, are some of its advantages. E.g.: Chlorella vulgaris, Spirulina platensis. [25]

\section{COMPARISON}

From all the above-mentioned methods, the mechanisms for generating Ag NPs, Physical Methods can be preferred as a top-notch method after tabular comparison with other mechanisms, see table 1 .

TABLE 1: COMPARISON BETWEEN VARIOUS MECHANISMS FOR THE SYNTHESIS OF SILVER NANOPARTICLES [8]

\begin{tabular}{|c|c|c|c|}
\hline METHOD $\Rightarrow$ & \multirow[t]{2}{*}{ PHYSICAL } & \multirow[t]{2}{*}{ CHEMICAL } & \multirow{2}{*}{ BIO } \\
\hline FEATURES & & & \\
\hline Type of Method & Green & Non-Green & Green \\
\hline Environment Friendly & Yes & No & Yes \\
\hline Hazardous Liquids & None & Yes & None \\
\hline Time consumed & $\begin{array}{c}\text { Timesavin } \\
\text { g }\end{array}$ & Long time & Long time \\
\hline Synthesised using & $\begin{array}{c}\text { Laser } \\
\text { Ablation }\end{array}$ & $\begin{array}{c}\text { Reducing } \\
\text { agents }\end{array}$ & $\begin{array}{l}\text { Bacteria, } \\
\text { Fungi, etc }\end{array}$ \\
\hline Resulted NPs & $\begin{array}{c}\text { Pure and } \\
\text { Uncontami } \\
\text { nated }\end{array}$ & $\begin{array}{c}\text { Chemically } \\
\text { Uncontamin } \\
\text { ated }\end{array}$ & $\begin{array}{c}\text { Organically } \\
\text { Uncontamin } \\
\text { ated }\end{array}$ \\
\hline
\end{tabular}

\section{TOP-NOTCH PREFERRED METHODS}

Pulsed Laser Ablation in Liquid (PLAL) under physical methods has the top-notch priority for synthesising Ag NPs of metallic bulk in liquid because it is a green method and consumes the lowest time \& finances as compared to 
traditional mechanisms. [26] [27] It is also introduced as a bottom-up process because of nucleation, advancement, \& gathering of clusters. With the interaction of ultrashort laser pulses $\left(10^{-13}-10^{-8} \mathrm{~s}\right)$, the generation of nanostructures from the solid bulk material substrate, is defined as laser ablation. Materials can be ablated in a vacuum, gas, or liquid mediums. [9] [28] [29] [40]

Moreover, the Ag NPs produced by laser ablation have rare properties as they are pure and uncontaminated metal colloids. The obtained efficiency and the characteristics of Ag NPs generated are based on several specifications, including the laser's wavelength $(\lambda)$, pulse duration and ablation time operating on the marker. [30] [31] This method is of high-quality and highly preferred because it produces metal colloids without any synthetic or organic assistance. Crucial specifications such as laser wavelength $(\lambda)$, pulse duration, \& the interaction of individual NP with a laser beam inside the liquid, influences the characteristics of NPs obtained in the liquid solution. NPs size distribution in aqueous solution is controlled either by spatial profiling of laser beam intensity or fine balancing of $\lambda$. [32] Some of the important parameters are briefed below:

a) Pulse Duration: PLAL is used for the generation of NP with pulse duration varying from Femto- to nanoseconds. NPs produced by PLAL, originate due to sputtering of the molten layer by the recoil pressure of the liquid around the targeted element. The temperature " $T$ " of the laser spot is expressed by the Simple heat balancing equation, i.e.:

$$
\mathrm{T} \approx \frac{\mathrm{Aj}}{\mathrm{c} \rho \mathrm{h}}
$$

Here, $\mathbf{A}$ - absorptivity of the targeted material $(\mathbf{A}=1-$ R) [R - reflectivity coefficient]

c - heat capacity of the targeted material,

$\boldsymbol{\rho}$ - density of the target material,

$\mathbf{h}$ - heat diffusion length inside the targeted material,

The heat diffusion length " $h$ " dependent on the heat diffusivity of the targeted element, expressed as:

$$
\mathrm{h} \propto \sqrt{\mathrm{at}_{\mathrm{p}}}
$$

wherein, $\mathrm{a}=\frac{\mathrm{k}}{\mathrm{c}}$, [k - heat conduction coefficient of the target, \& “ $\mathrm{t}_{\mathrm{p}}$ " - laser pulse duration].

Larger the $t_{p}$, thicker is the layer of the solid bulk which is fiery by absorbed laser energy. Also, for heating \& evaporation of a liquid adjacent to the laser spot, an amount of energy is consumed which is as small as to be neglected in comparison to the one absorbed because of lower thermal conductivity of liquids. [32]

b) Laser Wavelength: Any available wavelength is relevant when PLAL is considered. Undoubtedly, produced NPs can absorb laser radiation. Most of the
NPs absorb in UV range because of which the use of excimer UV lasers is least preferred. [32]

c) Repetition Rate: With each laser beam pulse (absorbed laser energy can melt the material), NPs are thrown out from the solid target. Therefore, the production of NPs is higher, provided the repetition rate of laser pulses is higher too. [32]

In the PLAL method, laser radiation is focused onto a solid target immersed in a liquid. It is assumed that the liquid is transparent at the laser wavelength, otherwise, the focalization of the beam would be problematic due to absorption of laser radiation in it. The simplest way is working with the free surface of the liquid, which allows avoiding additional reflection at the interface "covering glass/air". However, the use of volatile liquids, such as acetone, ethanol, etc., requires covering the liquid with a window that is transparent at the laser wavelength. [32]

The process of laser ablation works when nanostructures of noble metal are produced by pulsed laser ablation in liquid, see figure 1. [33] In the process, a metallic Ag target is placed in distilled water under a pulsed laser and is synthesised by the laser ablation. Various lasers can be used in the process such as Solid, Gas or chemical lasers of several wavelengths varying from picosecond to femtosecond. Laser ablated NPs have unique properties and are non-reproducible by any existing methods. [34]

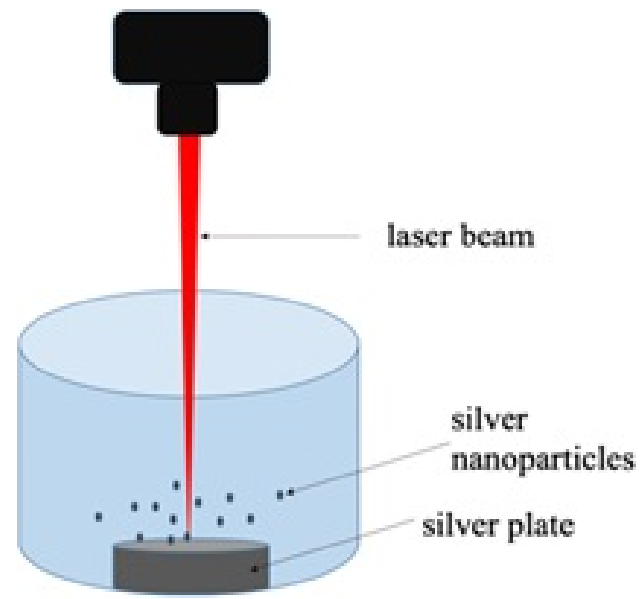

Figure 3: Systematic showing the working of the laser ablation process for producing silver nanoparticles [6]

To generate Ag NPs out of a metallic silver target through laser ablation, high-power pulsed lasers are required. Eventually, the ablation process relies on the physical features of the element used. The ablation rate is affected by several laser specifications including wavelength $(\lambda)$, fluence, pulse duration, repetition rate, the light absorption efficiency of the marked material, transmission, and chemical composition of the liquid. These laser parameters can be used to tune several NP features, such as size, shape, surface properties, aggregation state, solubility, structure, and chemical composition, see table 2. [8] 
TABLE 2: COMPARISON OF DIFFERENT PARAMETERS FOR PREPARING SILVER NANOPARTICLES VIA LASER ABLATION. [35] [36] [37]

\begin{tabular}{|c|c|c|c|}
\hline $\begin{array}{c}\text { Wavelength } \\
(\boldsymbol{\lambda})\end{array}$ & $532 \mathrm{~nm}$ & $800 \mathrm{~nm}$ & $1064 \mathrm{~nm}$ \\
\hline Laser & $\begin{array}{c}\text { Nd: YAG } \\
\text { (ns) }\end{array}$ & $\begin{array}{c}\text { Ti: Sapphire } \\
\text { (fs) }\end{array}$ & $\begin{array}{c}\text { Nd: YAG } \\
\text { (ns) }\end{array}$ \\
\hline $\begin{array}{c}\text { Mean } \\
\text { Diameter }\end{array}$ & $2-3 \mathrm{~nm}$ & $400 \mathrm{~nm}$ & $2-5 \mathrm{~nm}$ \\
\hline Absorbance & 0.28 & $>0.05$ & $<0.1$ \\
\hline Quantity & $\begin{array}{c}170 \mathrm{ml}(\mathrm{pure} \\
\text { water) }\end{array}$ & $\begin{array}{c}5 \mathrm{ml} \text { (deionised } \\
\text { water) }\end{array}$ & $\begin{array}{c}25 \mathrm{ml} \\
\text { (pure } \\
\text { water) }\end{array}$ \\
\hline
\end{tabular}

When compared, the formation efficiency and the size of colloidal pieces, was greater than those generated by a nanosecond laser. The nanosecond pulses have higher formation efficiency as of the femtosecond pulses. And the produced colloids by nanosecond pulses are more scattered than that of femtosecond pulses. Moreover, it was discovered that the ablation performance for femtosecond ablation in distilled water was diminishing than that in the air. In contrast, in the case of nanosecond pulses, the ablation energy was similar in both liquid and air. It was noted that self-absorption efficiency of Ag is superior at lower wavelengths than that of higher wavelengths, which concludes that the ablation energy with shorter-wavelength laser is lessened than that of a longer-wavelength laser. [35] [38] [41] [42]

\section{SUMMARY}

As Ag NPs possess unique properties, they are usable in various fields of science and technology, such as medicine, ecology, food industry, pharmacy, biotechnology, microelectronics, physics, and others. This is because Ag NPs are chemically stable and antimicrobial agents have a significant protective effect against microbial pathogens. Also, Ag NPs are not toxic to the human body in low concentrations. This makes them an integral part of the composition of various products with antimicrobial action.

These characteristics necessitated the active search and development of new technologies to produce Ag NPs with different shapes and sizes. Various teams from leading research laboratories study and improve the mechanisms of Ag NPs extraction, using chemical / synthetic reduction, laser ablation, electron beam exposure, concentrated microwave exposure, and many more.

Bio methods for NP synthesis have new possibilities for using organic and stabilizing agents. The proposal to use bio-organisms to extract NPs can contribute to the ecological purity of the environment. The biological activity of Ag NPs depends on factors including surface chemistry and morphology, size, shape, coating agent, NP agglomeration and dissolution rate, particle reactivity in solution, and ion release efficiency.

The flexibility of the chemical methods of Ag NPs and the rapid incorporation of $\mathrm{Ag}$ NPs into individual environments have motivated researchers to continue to study the mechanistic aspects of the antimicrobial, antiviral and anti-inflammatory effects of these NPs. This is achieved mainly through studies leading to a change in the form, size of Ag NPs by changing the reaction conditions, as well as the reagents and stabilizers used.

The laser ablation method to generate pure and uncontaminated metal NPs with unique properties, without the use of chemicals - organic or inorganic agents, has an exceptional environmental effect. In this method, laser parameters such as wavelength $(\lambda)$ and laser intensity turn out to be the most characteristic responsible for NP production, for example, green lasers show higher formation efficiency than infrared lasers, and nanosecond pulses of the laser cause a strong thermal effect.

\section{REFERENCES}

[1] J. W. Alexander, "History of the Medical Use of Silver," SURGICAL INFECTIONS, vol. 10 (3), 2009.

[2] V. D. L. I. A. v. B. A. Graf Christina, “A General Method To Coat Colloidal Particles with Silica,” Langmuir, vol. 19 (17), pp. 6693-6700, 11 July 2003.

[3] K. H. M. S. Z. B. Iravani S, “ Synthesis of silver nanoparticles: chemical, physical and biological methods," Research in Pharmaceutical Sciences, vol. 9, pp. 385-406, 2014.

[4] S. S., Biosynthesis and immobilization of nanoparticles and their applications, University of pune, 2005, pp. 1-57.

[5] G. R. P. J. Pareek V., "Do physico-chemical properties of silver nanoparticles decide their interaction with biological media and bactericidal action? A review.," Mater. Sci. Eng. C., vol. 90, pp. 739-749, 2018.

[6] Y. T. \&. B. V. Shu Zhang, "A Review on Preparation and Applications of Silver-Containing Nanofibers," Nanoscale Research Letters, vol. 80, 09 February 2016.

[7] H. F. K. a. M. H. Bernd Nowack, "120 Years of Nanosilver History: Implications for Policy Makers,” Environ. Sci. Technol., vol. 45(4), pp. 1177-1183, 10 January 2011.

[8] M. I. A. V. M. C. R. A. P. A. A. P. M. L. G. P. a. N. C. Maria Chiara Sportelli, "The Pros and Cons of the Use of Laser Ablation Synthesis for the Production of Silver NanoAntimicrobials,” Antibiotics (Basel), vol. 7, 28 July 2018.

[9] B. B. B. C. R. e. Manish Kothakonda, "Core-Shell Nanoparticles for Energy Storage Applications," in Pulsed Laser Ablation: Advances and Applications in Nanoparticles and Nanostructuring Thin Films, Pan Stanford Publishing Pte. Ltd., 2018, pp. 277-316.

[10] M. P. B. V. S. e. Vardan Galstyan, "Metal Oxide Nanostructures in Food Applications: Quality Control and Packaging," Chemosensors, vol. 6, no. 2, 14 April 2018.

[11] A. M.A.Virji, "8.06 - A Review of Engineered Nanomaterial Manufacturing Processes and Associated Exposures,” Comprehensive Materials Processing, vol. 8, pp. 103-125, 16 April 2014.

[12] L. G. C. E. M. e. Tomy Acsente, Tungsten Nanoparticles Produced by Magnetron Sputtering Gas Aggregation: Process Characterization and Particle Properties, London: IntechOpen, 2020.

[13] SPI LASERS LIMITED, [Online]. Available: https:/www.spilasers.com/application-ablation/what-is-laserablation/. 
[14] R. W. G. L. B. H. M. a. D. M. Getahun Merga, "Redox Catalysis on "Naked” Silver Nanoparticles," J. Phys. Chem. C, vol. 111, pp. 12220-12226, 2007.

[15] U. D. Z. D. Z. A. Oliveira M, “ Influence of synthetic parameters on the size, structure, and stability of dodecanethiol-stabilized silver nanoparticles,” J Colloid Interface Sci., vol. 292, pp. 429435, 2005.

[16] J. Y. Song and B. S. Kim, "Rapid biological synthesis of silver nanoparticles using plant leaf extracts," Bioprocess and Biosystems Engineering, vol. 32, pp. 79-84, 26042008.

[17] J. G. L. S.-Z. Qiao, "Chapter 21 - Synthetic Chemistry of Nanomaterials," in Modern Inorganic Synthetic Chemistry (Second Edition), Elsevier B.V., 2017, pp. 613-640.

[18] A. A. S. C. P. Suk Fun Chin, "Size Controlled Synthesis of Starch Nanoparticles by a Microemulsion Method," Journal of Nanomaterials, vol. 2014.

[19] A. H. J. Z. Y. X. C. M. L. Yong X. Gan, "Hydrothermal Synthesis of Nanomaterials,” Journal of Nanomaterials, vol. 2020

[20] S. B. S. A. R. Singaravelan, "Electrochemical synthesis, characterisation and phytogenic properties of silver nanoparticles,” Applied Nanoscience, vol. 5, no. 8, pp. 983-991, 18 January 2015.

[21] A. M. Hussein, Synthesis of silver nanoparticles, Mansoura University, 2016.

[22] S. Iravani, "Bacteria in Nanoparticle Synthesis: Current Status and Future Prospects,” vol. 2014.

[23] M. M. G. P. M. N. G. Palaniselvam Kuppusamy, "Biosynthesis of metallic nanoparticles using plant derivatives and their new avenues in pharmacological applications - An updated report," Saudi Pharmaceutical Journal, vol. 24, no. 4, pp. 473-484, July 2016.

[24] R. d. L. Mariana Guilger-Casagrande, "Synthesis of Silver Nanoparticles Mediated by Fungi: A Review," Bioeng. Biotechnol, vol. 7, 22 October 2019.

[25] S. V. M. A. e. Felix LewisOscar, Algal Nanoparticles: Synthesis and Biotechnological Potentials, London: IntechOpen, 2016.

[26] K. J. T. Y. K. T. S. H. Mafune F, "Structure and stability of silver nanoparticles in aqueous solution produced by laser ablation,” J Phys Chem B., vol. 104, pp. 8333-8337, 2000.

[27] S. A. V. V. S. G. B.-V. F. Dolgaev SI, "Nanoparticles produced by laser ablation of solids in liquid environment," Appl Surf Sci. vol. 186, pp. 546-551, 2002.

[28] a. M. M. Amendola V., "Laser ablation synthesis in solution and size manipulation of noble metal nanoparticles," Phys. Chem. Chem. Phys., vol. 11, pp. 3805-3821, 2009.

[29] F. M. a. M. T. Sakamoto M., "Light as a construction tool of metal nanoparticles: synthesis and mechanism," $j$. Photochem. Photobiol. C, vol. 10, no. 1, pp. 33-56, 2009.

[30] N. N. Kawasaki M, “1064-nm laser fragmentation of thin Au and Ag flakes in acetone for highly productive pathway to stable metal nanoparticles,” Appl Surf Sci., vol. 253, pp. 2208-2216, 2006.

[31] B. C. N. B. E.-S. M. Link S, "Laser-Induced shape changes of colloidal gold nanorods using femtosecond and nanosecond laser pulses.," J Phys Chem B., vol. 104, pp. 6152-6163, 2000.

[32] G. A. Shafeev, "FORMATION OF NANOPARTICLES UNDER LASER ABLATION OF SOLIDS IN LIQUIDS,” in Laser Ablation: Effects and Applications, New York, Nova Science Publishers, Inc., 2011, pp. 191-226.

[33] I. I. B. N. N. N. I. K. K. D. B. K. G. B. A. A. S. Nikolov, "Influence of the laser pulse repetition rate and scanning speed on the morphology of Ag nanostructures fabricated by pulsed laser ablation of solid target in water," Applied Physics : A Material science and processing, vol. 123, 27 October 2017.

[34] M. A. M. F. A. a. S. A. R. Amir Reza Sadrolhosseini, "Laser Ablation Technique for Synthesis of Metal Nanoparticle in Liquid,” in Laser Technology and its Applications, 2018.

[35] K. I. N. W. M. T. Takeshi Tsujia, "Preparation of silver nanoparticles by laser ablation in solution: influence of laser wavelength on particle size," Applied Surface Science, Vols. 202 (1-2), pp. 80-85, December 2002.

[36] B. S. H. A. K. Mohammad Zamakhsari Alhami, "Synthesis of silver nanoparticles using laser ablation Method utilizing Nd:YAG Laser,” AIP Conference Proceedings, vol. 2202, no. 1, 27 December 2019.

[37] K. S. M. Y. e. Alexander Pyatenko, "Synthesis of silver nanoparticlesby laser ablation in pure water," Applied Physics A, vol. 79, no. 4, pp. 803-806, September 2004.

[38] K. T. T. M. Tsuji T, "Preparation of nano-size particle of silver with femtosecond laser ablation in water.," Applied Surface Science, vol. 206, pp. 314-320, 2003.

[39] P. Singh Beer Pal, TOP-DOWN AND BOTTOM-UP APPROACHES FOR SYNTHESIS OF NANOMATERIALS.

[40] E. Teirumnieks, I. Balchev, R.S. Ghalot, and L. Lazov, "Antibacterial and anti-viral effects of silver nanoparticles in medicine against COVID-19 - A review". Laser Physics 31 (1), 013001. https://doi.org/10.1088/1555-6611/abc873

[41] L. Lazov, N. Angelov, E. Teirumnieks and E. Teirumnieka, "Preliminary numerical analysis for the role of speed onto laser technological processes”. Environment. Technology. Resources. Proceedings of the $12^{\text {th }}$ International Scientific and Practica Conference. Volume III. - Rezekne, 2019. - pp. 137. - 142. http://dx.doi.org/10.17770/etr2019vol3.4154

[42] P. Narica, L. Lazov, A. Teilans, P.Grabusts, E. Teirumnieks and P. Cacivkins, "Method for Color Laser Marking Process Optimization with the use of Genetic Algorithms". Environment. Technology. Resources. Proceedings of the $11^{\text {th }}$ International Scientific and Practical Conference. Volume II. - Rezekne, 2017. - pp. 101. - 106. http://dx.doi.org/10.17770/etr2017vol2.2607 